DE

M E D I C I N A

T R O P I C A L

$\mathrm{DE}$

SÃO PAULO

JOURNAL OF THE SÃO PAULO INSTITUTE OF TROPICAL MEDICINE
(1) Universidade Federal do Triângulo Mineiro, Programa de Pós-Graduação em Medicina Tropical e Infectologia, Uberaba, Minas Gerais, Brazil

(2) Instituto Federal de Educação, Ciência e Tecnologia do Triângulo Mineiro, Disciplinas de Microbiologia e Imunologia, Uberaba, Minas Gerais, Brazil

Correspondence to: Luciana de Almeida Silva Teixeira

Universidade Federal do Triângulo Mineiro, Programa de Pós-Graduação em Medicina Tropical e Infectologia, R. Getúlio Guaritá, s/n, CEP 38025-440, Uberaba, MG, Brazil

E-mail: luciana.teixeira@uftm.edu.br

Received: 27 March 2017

Accepted: 28 July 2017

\section{Prospective study of patients with persistent symptoms of dengue in Brazil}

\author{
Luciana de Almeida Silva Teixeira1, Fabiana Prado dos Santos Nogueira', \\ Gabriel Antonio Nogueira Nascentes ${ }^{2}$
}

\section{ABSTRACT}

Dengue is an arboviral infection clinically recognized as an acute and self-limited disease. Persistence of dengue symptoms is known, but it has been little studied. The aim of this study was to characterize persistent symptoms in 113 patients with dengue followed up clinically and by laboratory testing at a tertiary hospital. Symptoms that persisted for more than 14 days were observed in $61(54.0 \%)$ patients, and six (6.2\%) of them had symptoms for 6 months or more. The persistent symptoms identified were myalgia, weakness, hair loss, memory loss, reduced resistance to physical effort, headache, reasoning problems, arthralgia, sleepiness- and emotional lability. The progression to persistent symptoms was significantly associated with hospitalization, older age, more severe disease, the presence of bleeding and comorbidities upon univariate analysis. Upon multivariate analysis, the presence of persistent symptoms continued to be significantly associated only with increased age and dengue with warning signs. The platelet count during the acute phase of the disease was significantly lower in the group with persistent symptoms. In conclusion, the frequency of progression to persistent symptoms in dengue is relevant in patients seen at a tertiary hospital and the persistence of symptoms is more common in patients with dengue with warning signs.

KEYWORDS: Dengue. Clinical. Persistent symptoms

\section{INTRODUCTION}

Dengue is a viral disease transmitted by arthropods that occurs in more than 100 countries and whose incidence has been increasing over the past 50 years ${ }^{1}$. In 2013, based on the identification of 58.4 million cases of dengue worldwide, the aggregate global cost of the disease was estimated to be US\$ 8.9 billion $^{2}$. However, this number is probably underestimated because the additional costs resulting from the persistence of dengue symptoms in part of the affected population were not considered ${ }^{3}$.

Dengue fever is characterized as an acute febrile disease that lasts 1 to 2 weeks $^{4}$. However, literature data have called attention to the persistence of symptoms and laboratory alterations after the acute phase. Isolated cases of persistent symptoms were reported-and they were attributed to complications of the disease within specific contexts such as myositis ${ }^{5,6}$ and persistent thrombocytopenia ${ }^{7}$. Another study found that the persistence of symptoms is not a rare event, such as the occurrence of post-infectious fatigue syndrome in 27\% (31/127) of patients evaluated 2 months after the diagnosis of dengue ${ }^{8}$. Using different study designs, several authors have reported a wide variability in the prevalence of persistent symptoms according to the type of symptom, form of assessment and time of follow-up ${ }^{9-12}$. 
The present study prospectively investigated patients with dengue attended and followed up at a university hospital in Brazil to evaluate the persistence of symptoms and factors associated with this evolution.

\section{PATIENTS AND METHODS}

\section{Patients}

Patients seen at the University Hospital of the Federal University of Triângulo Mineiro (HC/UFTM), Uberaba, Minas Gerais, Brazil, between January 2012 and May 2015, were included.

The criteria for inclusion were age older than 14 years (minimum age of admission to the emergency department of the Clinic of HC/UFTM); hospitalized and/or receiving outpatient care (at least one outpatient visit) at the HC/UFTM; clinical suspicion of dengue recorded on the chart; positive serology for dengue (ELISA IgM or NS1) and agreement to participate in the study.

Patients who died were not included in the study since it was not possible to evaluate persistent symptoms of dengue in this group. The research was approved by the Ethics Committee of UFTM in 2011, Process No 1966.

\section{Serological diagnosis}

The ELISA IgM and NS1 assays were carried out at the referral services of the municipality, at the Macroregional Reference Laboratory and at the HC/UFTM using kits provided by the Brazilian Ministry of Health. All results were confirmed in the computerized exam registration system of the State of Minas Gerais (Gerenciador de Ambiente Laboratorial/GAL/Fundação Ezequiel Dias).

\section{Clinical data}

The signs and symptoms of the patients were systematically investigated using a specific clinical chart to characterize the acute phase of the disease (up to 14 days from the onset of symptoms). Spontaneous complaints were recorded and the patients were then asked about the presence of the following signs/symptoms and their respective duration: fever, headache, retro-orbital pain, myalgia, exanthema, prostration, arthralgia, nausea, vomiting, diarrhea, sleepiness, weakness, coryza- and cough. The patients were also questioned about spontaneous bleeding, warning signs (intense abdominal pain, persistent vomiting, painful hepatomegaly, pre-syncope, mucosal bleeding, sleepiness/irritability, and respiratory distress), date of onset and duration, and presence of signs of shock (hypotension, cold extremities, cyanosis, and rapid pulse). Information about the presence of comorbidities, history of medication use, allergies, and personal history of diseases was also obtained. Comorbidities were identified based on the patient's self-report, complementary tests, and previous medical follow-up.

In the case of patients hospitalized at the HC/UFTM, the records were reviewed to search for warning signs and signs of shock identified during medical care. Data reported by the patient were compared to those recorded during hospitalization at the HC/UFTM.

The participants underwent outpatient follow-up consisting of at least one weekly visit up to one month after the onset of symptoms and a monthly visit while the patient continued to report any symptom related to the disease. Additional visits were scheduled according to the clinical needs of patients. Another specific chart was used during the outpatient follow-up to record the spontaneous complaints of the patients and then applying the objective inquiry about the presence of fever, headache, retro-orbital pain, myalgia, exanthema, prostration, arthralgia, nausea, vomiting, diarrhea, sleepiness, weakness, coryza, cough, hair loss, cognitive state, memory loss, reasoning problems and skin changes. The objective signs were extracted from a survey of symptoms reported in a previous study ${ }^{10}$. All visits were conducted by at least one of the two participating physicians.

For the analysis, the presence of persistent symptoms of dengue was defined as the identification of previously non-existing symptoms lasting more than 14 days, which were attributed to the disease by the patient. Signs and symptoms that occurred up to two weeks of the disease onset were associated with the acute phase.

\section{Laboratory data}

The results of blood counts and liver tests (aspartate aminotransferase - AST, and alanine aminotransferase ALT) performed at the HC/UFTM during the follow-up of patients at the institution were requested. The number of repetitions of each test, the most altered value found and the day of disease on which the worst result was obtained were recorded. The results were collected using the Esmeralda computerized laboratory information system installed at the HC/UFTM.

The normal reference values for leukocytes were 4,000 to 10,000 cells $/ \mathrm{mm}^{3}$. Hematocrit was considered to be altered when $<30 \%$ for both genders, or $>50 \%$ for men and $>44 \%$ for women ${ }^{13}$. For platelets, values of 150,000 to 500,000 platelets $/ \mathrm{mm}^{3}$ were considered normal. The liver enzymes results were compared to the reference values and 
an increase was expressed as the number of times the result exceeds the upper limit of the reference range.

\section{Classification of dengue}

The patients of the study were classified into three groups: dengue, dengue with warning signs, and severe dengue. Since cases of dengue without fever have been recognized, dengue was considered when a clinical suspicion was made by the attending physician associated with a positive serological test. The parameters recommended by the World Health Organization (WHO) ${ }^{14}$ and by the Brazilian Ministry of Health ${ }^{13}$ were used for the groups classified as dengue with warning signs and severe dengue. Thus, the "dengue with warning signs" group was defined as the presence of dengue accompanied by at least one of the following signs/symptoms: severe abdominal pain, persistent vomiting, painful hepatomegaly, pre-syncope, bleeding, sleepiness/irritability, mucosal bleeding, and respiratory distress. The "severe dengue" group was defined as the presence of signs of shock (postural hypotension, cold extremities, cyanosis, and rapid pulse), severe hemorrhage (hematemesis and melena), and severe organ dysfunction (e.g., respiratory failure).

\section{Data analysis}

The association between each clinical parameter and the presence of persistent symptoms was evaluated using the classical chi-square test or Fisher exact test. The strength of the association was measured by calculating relative risks (RR) with 95\% confidence intervals (95\% CI). Age was compared in relation to the clinical parameters using the nonparametric Mann-Whitney or Kruskal-Wallis test, followed by the Dunn test. The statistical analyses were performed using the Statistica 10.0 software (Statsoft, Tulsa, OK, 2011) and MedCalc 12.2 programs (MedCalc Software, Ostend, Belgium). The level of significance was set at $\mathrm{p}<0.05$.

\section{RESULTS}

During the study period, 176 subjects with suspicion of dengue were seen at the HC/UFTM. Of these, 51 had no diagnostic confirmation (27 did not undergo serological testing and did not return to the service, 21 had negative serology and the ELISA IgM result was indeterminate in 3). In addition, of the 125 patients with a confirmed diagnosis of dengue, 7 died and 5 attended only one medical visit. Thus, 113 patients were followed up during the study until medical discharge and all of them presented clinical suspicion and serological diagnostic confirmation (93 positive ELISA IgM and 20 positive NS1).

Of the 113 patients included in the study, $49(43.4 \%)$ were hospitalized at the HC/UFTM, which is a tertiary hospital. The most frequent reason for admission was evidence of bleeding accompanied or not by thrombocytopenia in 35 patients (31.0\%). There was agreement between the warning signs and signs of shock reported by the patients and those recorded during hospitalization at the HC/UFTM. The presence of persistent symptoms was observed in 61 (54.0\%) of the patients in this study. Demographic data of patients are shown in Table 1.

Table 1 - Demographic data of the 113 patients with dengue in the study

\begin{tabular}{|c|c|c|}
\hline Characteristics & $\mathrm{n}$ & $\%$ \\
\hline \multicolumn{3}{|l|}{ Gender } \\
\hline Male & 42 & 37.2 \\
\hline Female & 71 & 62.8 \\
\hline \multicolumn{3}{|l|}{ Age (years) } \\
\hline $14-30$ & 43 & 38.1 \\
\hline $30-60$ & 55 & 48.7 \\
\hline$>60$ & 15 & 13.3 \\
\hline \multicolumn{3}{|l|}{ Hospitalization } \\
\hline No & 62 & 54.9 \\
\hline Yes & 49 & 43.4 \\
\hline Unknown & 2 & 1.8 \\
\hline \multicolumn{3}{|l|}{ Classification of dengue } \\
\hline Dengue & 62 & 54.9 \\
\hline Dengue with warning signs & 45 & 39.8 \\
\hline Severe dengue & 6 & 5.3 \\
\hline \multicolumn{3}{|l|}{ Reason for hospitalization } \\
\hline Bleeding/thrombocytopenia & 35 & 31.0 \\
\hline Abdominal pain/hepatomegaly & 19 & 16.8 \\
\hline $\begin{array}{l}\text { Pre-syncope/lethargy/mental confusion/ } \\
\text { sleepiness }\end{array}$ & 8 & 7.1 \\
\hline Respiratory distress & 8 & 7.1 \\
\hline Persistent vomiting & 7 & 6.2 \\
\hline Shock/signs of shock & 4 & 3.5 \\
\hline Respiratory failure & 3 & 2.7 \\
\hline Other & 4 & 3.5 \\
\hline \multicolumn{3}{|l|}{ Comorbidity } \\
\hline No & 49 & 43.4 \\
\hline Yes & 63 & 55.8 \\
\hline Unknown & 1 & 0.9 \\
\hline \multicolumn{3}{|l|}{ Persistent symptoms } \\
\hline No & 52 & 46.0 \\
\hline Yes & 61 & 54.0 \\
\hline
\end{tabular}


Evaluation of the initial symptoms of dengue showed that only $100(88.5 \%)$ of the patients reported fever. The most common symptom was weakness accompanied or not by prostration, reported by 111 (98.2\%) of the participants. The frequency of the other signs and symptoms was headache in 100 (88.5\%) patients, nausea in $86(76.1 \%)$, retro-orbital pain in 75 (66.4\%), exanthema in 71 (62.8\%), sleepiness in 71 (62.8\%), arthralgia in $63(55.8 \%)$, diarrhea in $55(48.7 \%)$, vomiting in 39 (34.5\%), cough in $34(30.1 \%)$, abdominal pain in $23(20.4 \%)$, coryza in $19(16.8 \%)$, and pruritus in $18(15.9 \%)$.

Myalgia and weakness were the two most common symptoms during the acute phase of the disease and among the persistent symptoms. Recurrent symptoms that had not been previously established in the directed interview were identified. The most common symptoms were reduced resistance to physical effort and emotional lability. In the 61 patients with persistent symptoms, the duration of symptoms ranged from 1 to 12 months. Symptoms persisted for up to one month in $27(44.3 \%)$ patients, for 2 to 5 months in 27 (44.3\%), and for 6 months or more in $7(11.5 \%)$ patients. No specific therapeutic intervention was performed and the symptoms resolved over time. The main persistent signs and symptoms of the disease are listed in Table 2.

The presence of comorbidities and persistent symptoms increased significantly with age (Table 3 ). The most frequent comorbidities were systemic arterial hypertension in $19(30.2 \%)$ patients, hypothyroidism in $9(14.3 \%)$ and diabetes mellitus in $6(9.5 \%)$ patients. All comorbidities are described in Table 4.
Table 2 - Most common persistent symptoms shown by the patients during the study

\begin{tabular}{lcc}
\hline $\begin{array}{l}\text { Most common } \\
\text { persistent }\end{array}$ symptoms & $\begin{array}{c}\text { \% Among all } \\
\text { patients } \\
(\mathrm{n}=113)\end{array}$ & $\begin{array}{c}\text { \% Among patients } \\
\text { with persistent } \\
\text { symptoms }(\mathrm{n}=61)\end{array}$ \\
\hline Myalgia & 25.7 & 47.5 \\
Weakness & 22.1 & 41.0 \\
Hair loss & 19.5 & 36.1 \\
Memory loss & 15.9 & 29.5 \\
Reduced resistance & 15.0 & 27.9 \\
to physical effort & & 24.6 \\
Headache & 13.3 & 24.6 \\
Reasoning & 13.3 & 21.3 \\
problems & & 19.7 \\
Arthralgia & 11.5 & 8.2 \\
Sleepiness & 10.6 & \\
Emotional lability & 4.4 & \\
\hline
\end{tabular}

A total of 481 blood counts, 283 AST measurements and 272 ALT measurements were obtained from the 113 patients followed up in this study.

During the acute phase of the disease, an altered hematocrit value was observed in only 17 (15\%) patients, including 12 (10.6\%) with increased hematocrit and five with low hematocrit, associated with severe bleeding. Among the 45 patients classified as dengue with warning signs, $39(87 \%)$ had no altered hematocrit value. Thrombocytopenia was observed in $80(71 \%)$ patients and was more common on day 6 of the disease. Leukopenia was present in $66(58 \%)$ patients and was more common

Table 3 - Association between age and clinical parameters in patients with dengue

\begin{tabular}{lccc}
\hline \multirow{2}{*}{ Clinical parameter } & \multicolumn{2}{c}{ Age (years) } & p-value \\
\cline { 2 - 3 } & Mean $( \pm \text { SD })^{1}$ & $\begin{array}{c}\text { Median } \\
\text { (minimum-maximum) }\end{array}$ & \\
\hline Classification of dengue & $39.2 \pm 15.4$ & $38.5(17.0-80.0)$ & 0.105 \\
$\quad$ Dengue & $41.4 \pm 19.2$ & $39.0(14.0-92.0)$ & \\
$\quad$ Dengue with warning signs & $55.3 \pm 18.0$ & $57.5(35.0-84.0)$ & \\
$\quad$ Severe dengue & $31.1 \pm 12.1$ & $27.0(14.0-60.0)$ & $<0.001$ \\
Comorbidity & $48.6 \pm 17.2$ & $49.0(17.0-92.0)$ & \\
$\quad$ No & & & \\
$\quad$ Yes & $32.9 \pm 12.3$ & $29.0(14.0-64.0)$ & $<0.001$ \\
Persistent symptoms & $47.8 \pm 17.6$ & $48.0(15.0-92.0)$ & \\
$\quad$ No & & & \\
$\quad$ Yes & & & \\
\hline
\end{tabular}

${ }^{1}$ The results are expressed as the mean \pm standard deviation. ${ }^{2}$ The $p$-value refers to the result of the nonparametric Mann-Whitney test for comparison between two independent samples (comorbidity, persistent symptoms), or of the Kruskal-Wallis test for comparison between three independent samples (WHO classification). 
Table 4 - Comorbidities shown by 63 patients in the study

\begin{tabular}{|c|c|c|}
\hline Comorbidity & $\mathrm{n}$ & $\%$ \\
\hline Systemic arterial hypertension & 8 & 12.7 \\
\hline Diabetes mellitus & 3 & 4.8 \\
\hline Gastroesophageal reflux & 3 & 4.8 \\
\hline Hypothyroidism & 3 & 4.8 \\
\hline Aids & 3 & 4.8 \\
\hline Dyslipidemia & 2 & 3.2 \\
\hline Alcohol use disorder & 1 & 1.6 \\
\hline Linfoma in remission & 1 & 1.6 \\
\hline Glaucoma & 1 & 1.6 \\
\hline Migraine & 1 & 1.6 \\
\hline Cardiopathy, ischemic & 1 & 1.6 \\
\hline Post bariatric surgery & 1 & 1.6 \\
\hline Morbid obesity & 1 & 1.6 \\
\hline Thyroid gland cancer & 1 & 1.6 \\
\hline Chagas disease & 1 & 1.6 \\
\hline Hydronephrosis & 1 & 1.6 \\
\hline Idiopathic thrombocytopenic purpura & 1 & 1.6 \\
\hline Vitiligo & 1 & 1.6 \\
\hline Asthma & 1 & 1.6 \\
\hline Pituitary adenoma & 1 & 1.6 \\
\hline Depression & 1 & 1.6 \\
\hline Prostatic hyperplasia & 1 & 1.6 \\
\hline Systemic arterial hypertension and biliary lithiasis & 1 & 1.6 \\
\hline Systemic arterial hypertension and aids & 1 & 1.6 \\
\hline Systemic arterial hypertension and valve disease & 1 & 1.6 \\
\hline Systemic arterial hypertension and hypothyroidism & 1 & 1.6 \\
\hline Systemic arterial hypertension and chronic obstructive pulmonary disease & 1 & 1.6 \\
\hline Systemic arterial hypertension and peptic ulcer disease & 1 & 1.6 \\
\hline Epilepsy and arthrosis & 1 & 1.6 \\
\hline Depression and meningitis sequela & 1 & 1.6 \\
\hline Allergic rhinitis and hypothyroidism & 1 & 1.6 \\
\hline Depression and chronic anemia & 1 & 1.6 \\
\hline Hypoacusis and late-onset dementia & 1 & 1.6 \\
\hline Hypoacusis and cardiac arrhythmia & 1 & 1.6 \\
\hline Labyrinthitis and arthrosis & 1 & 1.6 \\
\hline Psoriasis and hemorrhoids & 1 & 1.6 \\
\hline Systemic arterial hypertension, congestive heart failure and chronic renal insufficiency & 1 & 1.6 \\
\hline Systemic arterial hypertension, Chagas disease and breast cancer & 1 & 1.6 \\
\hline Systemic arterial hypertension, breast cancer and arthrosis & 1 & 1.6 \\
\hline Systemic arterial hypertension, diabetes mellitus and arthrosis & 1 & 1.6 \\
\hline Systemic arterial hypertension, fibromyalgia and hypothyroidism & 1 & 1.6 \\
\hline Diabetes mellitus, hypothyroidism and depression & 1 & 1.6 \\
\hline Allergic rhinitis, sinusitis and recurrent otitis & 1 & 1.6 \\
\hline Chronic myeloid leukemia, rhinitis and gastritis & 1 & 1.6 \\
\hline Rheumatoid arthritis, Sjögren syndrome and fibromyalgia & 1 & 1.6 \\
\hline Diabetes mellitus, hypothyroidism, osteoporosis and dyslipidemia & 1 & 1.6 \\
\hline Epilepsy, hypothyroidism and chronic renal insufficiency & 1 & 1.6 \\
\hline
\end{tabular}


on day 4, elevated AST was observed in $68(60 \%)$ and was more common on day 7, and elevated ALT was observed in $63(56 \%)$ and was more common on day 8 of the disease.

A significant association was observed between altered hematocrit, AST and ALT and the dengue with warning signs (RR: $1.3 ; 1.8 ; 1.9$, respectively) and severe dengue (RR: $8.2 ; 1.8 ; 2.4$, respectively). When compared to the presence of persistent symptoms, the association was significant only with altered ALT (RR: 1.5) (Table 5).

The progression to persistent symptoms was significantly associated with older age (30-60 years RR: 2.2; $>60$ years RR; 2.7), dengue with warning signs (RR: 2.1), severe dengue (RR: 2.4), hospitalization (RR: 1.5), presence of bleeding (RR: 1.6), respiratory discomfort (RR: 1.7), and comorbidities (RR: 1.6) (Table 6).

\section{DISCUSSION}

The WHO, and consequently the Brazilian protocols that are based on its recommendation, defines the presence of fever accompanied by two or more of the following criteria as the diagnosis of probable dengue: nausea/vomiting, exanthema, myalgia, headache, positive tourniquet test or any warning sign ${ }^{13,14}$. In the present study, individuals with symptoms compatible with the disease, which led to a clinical suspicion by the attending physician even in the absence of fever, were considered suspected cases of dengue. In this respect, about $10 \%$ of all evaluated participants did not report fever and the diagnosis would not have been made if the classical definition of the disease would have been followed. On the other hand, of the 13 individuals without fever, only in 3 of them the illness was confirmed by NS1 and in 10 by ELISA IgM. Considering that IgM has also been used in an unreported number of patients to establish the diagnosis of the disease and it can remain positive for some months, it is not possible to rule out the hypothesis of some other infection instead of dengue.

The prevalence of dengue with persistent symptoms reported in the literature varies widely, from 2 to $68 \%{ }^{3}$. In contrast to a retrospective study previously published by our group, the prospective follow-up of patients in the present study provided more reliable information. Nevertheless, the prevalence of persistent symptoms was similar to that found in the previous retrospective study, $50-60 \%{ }^{10}$.

The most common persistent symptoms of dengue reported in different studies were myalgia ${ }^{11}$, arthralgia $^{15}$, and headache ${ }^{12}$. Other prevalent symptoms include weakness, adynamia, fatigue and asthenia ${ }^{8,9,11,12,15,16}$, whose duration can reach 2 years ${ }^{11}$. These symptoms were also the most frequent in the present study. However, the marked presence of other symptoms such as hair loss, memory loss, reasoning problems, sleepiness and emotional lability should be highlighted. The repercussions of these persistent symptoms on the work capacity and quality of life of affected individuals require further investigation ${ }^{17}$.

The global economic impact of dengue involves an

Table 5 - Comparison between altered laboratory tests and the clinical parameter in patients with dengue

\begin{tabular}{|c|c|c|c|c|c|}
\hline \multirow[b]{2}{*}{ Clinical parameter } & \multicolumn{5}{|c|}{ Altered laboratory test } \\
\hline & Hematocrit & Leukocytes & Platelets & $\begin{array}{c}\text { Aspartate } \\
\text { transaminase }\end{array}$ & $\begin{array}{c}\text { Alanine } \\
\text { transaminase }\end{array}$ \\
\hline \multicolumn{6}{|l|}{ Persistent symptoms } \\
\hline No & $5 / 49(10.2 \%)$ & $35 / 49(71.4 \%)$ & $37 / 49(75.5 \%)$ & $27 / 49(55.1 \%)$ & $22 / 49(44.9 \%)$ \\
\hline Yes & $12 / 61(19.7 \%)$ & $36 / 60(60.0 \%)$ & $43 / 61(70.5 \%)$ & $41 / 61(67.2 \%)$ & $41 / 61(67.2 \%)$ \\
\hline $\operatorname{RR}(95 \% \mathrm{Cl})^{1}$ & $1.9(0.7-5.1)$ & $0.8(0.6-1.1)$ & $0.9(0.7-1.2)$ & $1.2(0.9-1.7)$ & $1.5(1.1-2.1)$ \\
\hline p-value* & 0.172 & 0.213 & 0.557 & 0.194 & 0.019 \\
\hline \multicolumn{6}{|l|}{ Clinical Classification } \\
\hline Dengue & $6 / 59(10.2 \%)$ & $41 / 58(70.7 \%)$ & $41 / 59(69.5 \%)$ & $27 / 59(45.8 \%)$ & 23/59 (39.0\%) \\
\hline Dengue with warning signs & 6/45 (13.3\%) & $26 / 45(57.8 \%)$ & $33 / 45(73.3 \%)$ & $36 / 45(80.0 \%)$ & $34 / 45(75.6 \%)$ \\
\hline Severe dengue & $5 / 6(83.3 \%)$ & $4 / 6(66.7 \%)$ & $6 / 6(100.0 \%)$ & $5 / 6(83.3 \%)$ & $6 / 6(100.0 \%)$ \\
\hline $\mathrm{RR}(95 \% \mathrm{Cl})^{2}$ & $1.3(0.5-3.8)$ & $0.8(0.6-1.1)$ & $1.1(0.8-1.4)$ & $1.8(1.3-2.4)$ & $1.9(1.4-2.8)$ \\
\hline $\mathrm{RR}(95 \% \mathrm{Cl})^{3}$ & $8.2(3.5-19.0)$ & $0.9(0.5-1.7)$ & $1.3(0.9-1.8)$ & $1.8(1.2-2.9)$ & $2.4(1.6-3.5)$ \\
\hline$p$-value* & $<0.001$ & 0.393 & 0.277 & 0.001 & $<0.001$ \\
\hline
\end{tabular}

* The p-value corresponds to the result of the chi-square test. For parameters with $\mathrm{p}<0.05$. RR $(95 \% \mathrm{Cl})^{1}$ indicates the risk of individuals with a diagnosis of dengue and persistent symptoms to have altered laboratory tests compared to patients without persistent symptoms. RR $(95 \% \mathrm{Cl})^{2}$ indicates the risk of individuals with a diagnosis of dengue and warning signs to have altered laboratory tests compared to patients with dengue. RR $(95 \% \mathrm{Cl})^{3}$ indicates the risk of individuals with severe dengue to have altered laboratory tests compared to patients with dengue. 
Table 6 - Univariate analysis of the association between persistent symptoms and clinical variables

\begin{tabular}{|c|c|c|c|}
\hline Variables & $\begin{array}{c}\text { Presence of persistent } \\
\text { symptoms }\end{array}$ & $\mathrm{RR}(95 \% \mathrm{Cl})^{1}$ & $\mathrm{p}$-value \\
\hline \multicolumn{4}{|l|}{ Gender } \\
\hline Male & 22/42 (52.4\%) & 1.0 & 0.793 \\
\hline Female & $39 / 71(54.9 \%)$ & $1.1(0.7-1.5)$ & \\
\hline \multicolumn{4}{|l|}{ Age (years) } \\
\hline$<30$ & $13 / 43(30.2 \%)$ & 1.0 & $<0.001$ \\
\hline $30-60$ & $36 / 55(65.5 \%)$ & $2.2(1.3-3.5)$ & \\
\hline$>60$ & $12 / 15(80.0 \%)$ & $2.7(1.6-4.5)$ & \\
\hline \multicolumn{4}{|l|}{ Classification of dengue } \\
\hline Dengue & $22 / 62(35.5 \%)$ & 1.0 & $<0.001$ \\
\hline Dengue with warning signs & $34 / 45(75.6 \%)$ & $2.1(1.5-3.1)$ & \\
\hline Severe dengue & $5 / 6(83.3 \%)$ & $2.4(1.4-3.8)$ & \\
\hline \multicolumn{4}{|l|}{ Hospitalization } \\
\hline No & $27 / 62(43.6 \%)$ & 1.0 & 0.024 \\
\hline Yes & $32 / 49(65.3 \%)$ & $1.5(1.1-2.1)$ & \\
\hline \multicolumn{4}{|l|}{ Bleeding/thrombocytopenia } \\
\hline No & $36 / 78(46.2 \%)$ & 1.0 & 0.013 \\
\hline Yes & $25 / 35(71.4 \%)$ & $1.6(1.1-2.1)$ & \\
\hline \multicolumn{4}{|c|}{ Pre-syncope/lethargy/mental confusion/sleepiness } \\
\hline No & $57 / 105(54.3 \%)$ & 1.0 & 1.000 \\
\hline Yes & $4 / 8(50.0 \%)$ & $0.9(0.5-1.9)$ & \\
\hline \multicolumn{4}{|l|}{ Abdominal pain/hepatomegaly } \\
\hline No & $48 / 94(51.1 \%)$ & 1.0 & 0.166 \\
\hline Yes & $13 / 19(68.4 \%)$ & $1.3(0.9-1.9)$ & \\
\hline \multicolumn{4}{|l|}{ Shock/signs of shock } \\
\hline No & $58 / 109(53.2 \%)$ & 1.0 & 0.623 \\
\hline Yes & $3 / 4(75.0 \%)$ & $1.4(0.8-2.6)$ & \\
\hline \multicolumn{4}{|l|}{ Respiratory distress } \\
\hline No & $54 / 105(51.4 \%)$ & 1.0 & 0.048 \\
\hline Yes & $7 / 8(87.5 \%)$ & $1.7(1.2-2.4)$ & \\
\hline \multicolumn{4}{|l|}{ Persistent vomiting } \\
\hline No & $55 / 106(51.9 \%)$ & 1.0 & 0.122 \\
\hline Yes & 6/7 (85.7\%) & $1.7(1.0-2.4)$ & \\
\hline \multicolumn{4}{|l|}{ Respiratory failure } \\
\hline No & $59 / 110(53.6 \%)$ & 1.0 & 1.000 \\
\hline Yes & $2 / 3(66.7 \%)$ & $1.2(0.6-2.8)$ & \\
\hline \multicolumn{4}{|l|}{ Comorbidity } \\
\hline No & $20 / 49(40.8 \%)$ & 1.0 & 0.017 \\
\hline Yes & $40 / 63(63.5 \%)$ & $1.6(1.1-2.3)$ & \\
\hline
\end{tabular}

${ }^{1} \mathrm{RR}(95 \% \mathrm{Cl})$ : relative risk with $95 \%$ confidence interval. ${ }^{2} \mathrm{Classical}$ chi-square test or Fisher exact test. 
annual cost of the disease of US\$ 8.9 billion. Considering published data on the persistence of dengue symptoms, Tiga et al. ${ }^{3}$ estimated a $43 \%$ increase in the impact attributed to persistent symptoms over previous estimates.

Other variables associated with persistent symptoms are gender and age. An association of female gender and advanced age with the presence of persistent symptoms has been observed in other studies ${ }^{3,11,12}$. This would be consistent with the view that older patients have a lower regenerative capacity of affected tissues and would, therefore, take longer to recover from the disease. In the case of female gender, other factors such as reproductive function, genetic constitution and psychosomatic factors need to considered. In the present study, the variables associated with the progression to persistent symptoms were older age, dengue with warning signs, severe dengue, hospitalization, presence of bleeding, respiratory distress and comorbidities. No association with gender was observed. This result may be explained by the size of the analyzed sample, especially the small number of patients with severe dengue and the impact of the disease in older individuals who are more frequently affected by comorbidities and are more likely to be hospitalized.

Regarding the results of the laboratory tests, most patients classified as dengue with warning signs showed no alterations in hematocrit on admission or during evolution of the disease. In the case of patients with normal hematocrit, this parameter loses its utility as a marker of adequate hydration as recommended by the $\mathrm{WHO}^{13,14}$. On the other hand, alterations in hematocrit were significantly associated with severity. Thus, hematocrit alterations should be considered if present, but their absence does not exclude severe disease.

Liver involvement has been reported to be relatively common in dengue and is characterized by necrosis and apoptosis of hepatocytes and Kupffer cells induced by the dengue virus itself ${ }^{18}$. Transaminase levels as a measure of liver damage have been used in several studies and increased levels of these enzymes have been associated with a poor prognosis ${ }^{19-21}$. Increased liver enzymes were observed in $60 \%$ of the patients and increased ALT levels were associated with the progression to persistent symptoms of dengue.

A limitation of the present study is the fact that only patients seen at a tertiary hospital were included. Thus, the present results may not reflect what happens to cases seen in primary care. To analyze the presence or absence of hospitalization, only the records of the HC/UFTM and the information provided by the patients were analyzed as it was not possible to track hospitalizations in other medical units. Regarding the characterization of persistent symptoms, the report of the patients was subjective on many occasions (e.g., limitation of physical effort), a fact that impairs the collection of more precise information about the intensity of symptoms. Furthermore, the frequency of persistent symptoms might have been overestimated since only patients who were regularly seen at the HC/UFTM until medical discharge were included.

The present results confirm the persistence of symptoms attributed to dengue for prolonged periods and its association with advanced age and severity of the disease. Further studies are needed to characterize the physiopathogenic factors of the disease associated with the progression to persistent symptoms, as well as the repercussion of these symptoms on the social and economic life of affected patients.

\section{ACKNOWLEDGMENTS}

We thank the UFTM medical students Rafael Silva Côrtes and Isabela Borges de Melo for their help with the creation of a specific outpatient clinic for patients with dengue.

\section{REFERENCES}

1. Guzman MG, Harris E. Dengue. Lancet. 2015;385:453-65.

2. Shepard DS, Undurraga EA, Halasa YA, Stanaway JD. The global economic burden of dengue: a systematic analysis. Lancet Infect Dis. 2016;16:935-41.

3. Tiga DC, Undurraga EA, Ramos-Castañeda J, Martínez-Vega RA, Tschampl CA, Shepard DS. Persistent symptoms of dengue: estimates of incremental disease and economic burden in Mexico. Am J Trop Med Hyg. 2016;94:1085-9.

4. Simmons CP, Farrar JJ, Chau NV, Wills B. Dengue. N Engl J Med. 2012;366:1423-32.

5. Lim M, Goh HK. Rhabdomyolysis following dengue virus infection. Singapore Med J. 2005;46:645-6.

6. Finsterer J, Kongchan K. Severe, persisting, steroid-responsive dengue myositis. J Clin Virol. 2006;35:426-8.

7. Kohli U, Saharan S, Lodha R, Kabra SK. Persistent thrombocytopenia following dengue shock syndrome. Indian J Pediatr. 2008;75:82-3.

8. Seet RC, Quek AM, Lim EC. Post-infectious fatigue syndrome in dengue infection. J Clin Virol. 2007;38:1-6.

9. Low JG, Ooi EE, Tolfvenstam T, Leo YS, Hibberd ML, Ng LC, et al. Early dengue infection and outcome study (EDEN) - study design and preliminary findings. Ann Acad Med Singapore. 2006:35:783-9.

10. Teixeira LA, Lopes JS, Martins AG, Campos FA, Miranzi SS, Nascentes GA. Persistência dos sintomas de dengue em uma população de Uberaba, Minas Gerais, Brasil. Cad Saude Publica. 2010;26:624-30. 
11. García G, González N, Pérez AB, Sierra B, Aguirre E, Rizo D, et al. Long-term persistence of clinical symptoms in dengueinfected persons and its association with immunological disorders. Int J Infect Dis. 2011;15:e38-43.

12. Halsey ES, Williams M, Laguna-Torres VA, Vilcarromero S, Ocaña V, Kochel TJ, et al. Occurrence and correlates of symptom persistence following acute dengue fever in Peru. Am J Trop Med Hyg. 2014;90:449-56.

13. Brasil. Ministério da Saúde. Secretaria de Vigilância em Saúde. Secretaria de Atenção à Saúde. Departamento de Vigilância das Doenças Transmissíveis. Dengue: diagnóstico e manejo clínico: adulto e criança. Brasília: $5^{\text {a }}$ ed. Ministério da Saúde; 2016. [cited 2017 July 28]. Available from: http://portalsaude. saude.gov.br/images/pdf/2016/janeiro/14/dengue-manejoadulto-crianca-5d.pdf

14. World Health Organization. Dengue: guidelines for diagnosis, treatment, prevention and control. Geneva: WHO; 2009. [cited 2017 July 28]. Available from: http://www.who.int/tdr/ publications/documents/dengue-diagnosis.pdf?ua=1

15. Tristão-Sá R, Kubelka CF, Zandonade E, Zagne SM, Rocha NS, Zagne LO, et al. Clinical and hepatic evaluation in adult dengue patients: a prospective two-month cohort study. Rev Soc Bras Med Trop. 2012;45:675-81.

16. Dettogni RS, Tristão-Sá R, Santos M, Silva FF, Louro ID. Single nucleotide polymorphisms in immune system genes and their association with clinical symptoms persistence in dengueinfected persons. Hum Immunol. 2015;76:717-23.

17. Lum LC, Suaya JA, Tan LH, Sah BK, Shepard DS. Quality of life of dengue patients. Am J Trop Med Hyg. 2008;78:862-7.

18. Martina BE, Koraka P, Osterhaus AD. Dengue virus pathogenesis: an integrated view. Clin Microbiol Rev. 2009;22:564-81.

19. Parkash O, Almas A, Jafri SM, Hamid S, Akhtar J, Alishah H. Severity of acute hepatitis and its outcome in patients with dengue fever in a tertiary care hospital Karachi, Pakistan (South Asia). BMC Gastroenterol. 2010;10:43.

20. Trung DT, Thao TT, Hien TT, Hung NT, Vinh NN, Hien PT, et al. Liver involvement associated with dengue infection in adults in Vietnam. Am J Trop Med Hyg. 2010;83:774-80.

21. Djossou F, Vesin G, Walter G, Epelboin L, Mosnier E, Bidaud B, et al. Incidence and predictive factors of transaminase elevation in patients consulting for dengue fever in Cayenne Hospital, French Guiana. Trans R Soc Trop Med Hyg. 2016;110:134-40. 